\title{
MAL DE ARQUIVO EM LINDEN HILLS
}

Sonia Torres ${ }^{1^{*}}$

Rita de Cássia Marinho de Paiva ${ }^{2 *}$

${ }^{1,2}$ Universidade Federal Fluminense, Niterói, Rio de Janeiro, Brasil

Resumo

Neste artigo, examinamos o romance Linden Hills, de Gloria Naylor, articulando os conceitos de neo-arquivo e a chamada neonarrativa de escravidão com a noção de arquivo proposta por Derrida (2001), e desenvolvida por autores com os quais buscamos o diálogo neste espaço (Osborne,1999; Bradley,1999; Johnson, 2014). A narrativa contradiscursiva de Linden Hills revisita o passado, através da escavação do palimpsesto de memórias individuais e coletivas, outrora esquecidas, não identificadas, estabelecendo, assim, seu parentesco com as neonarrativas. Entendemos que o vínculo da neonarrativa de escravidão com o arquivo, por sua vez, é bastante concreto e produtivo, pois traz a lume os arquivos não-sancionados que funcionam como contranarrativas ao arquivo histórico (sobretudo, mas não somente, o da escravidão), através da articulação da história com a memória, pessoal e coletiva - questionando, desta forma, a história documentada pelo colonizador e guardada por seus arcontes oficiais.

Palavras-chave: Gloria Naylor; Arquivos Contradiscursivos; Memória; Neonarrativa de Escravidão.

\section{ARCHIVE FEVER IN LINDEN HILLS}

\section{Abstract}

In this article we examine Gloria Naylor's novel Linden Hills, articulating the concepts of the neoarchive and the neo-slave narrative with the notion of archive as proposed by Derrida (2001) and developed by other authors (Osborne,1999; Bradley,1999; Johnson, 2014) with whom we seek to dialogue in this space. Linden Hills's counterdiscursive narrative revisits the past by excavating the palimpsest of forgotten memories, once unidentified or not compiled, thus establishing its relationship to the neo-

\footnotetext{
" Professora Titular do Instituto de Letras da UFF, onde atua no Programa de Pós-Graduação em Estudos de Literatura. Tem mestrado em Literaturas de Língua Inglesa (UFRJ), doutorado em Ciência da Literatura/ Literatura Comparada (UFRJ) e pós-doutorados pela UNIRIO e PACC/UFRJ. É bolsista de Produtividade em Pesquisa do $\mathrm{CNPq}$, e os termos mais frequentes na contextualização de sua produção científica são: diáspora, memória, arquivo; performance, terror, identidades políticas; pós-humanismo, ficção especulativa; antropoceno/antropo-cenas. Seu e-mail é sonia.torres@terra.com.br. ORCID: https://orcid.org/0000-00023114-9743.

** Professora do Ensino Básico Técnico e Tecnológico (EBTT) do quadro do Magistério Civil da Marinha do Brasil, onde atua como professora de Inglês. Tem mestrado em Linguística Aplicada (UFRJ) e é doutoranda do Programa de Pós-Graduação em Estudos de Literatura da Universidade Federal Fluminense (UFF), na linha de pesquisa "Literatura, História e Cultura". Seu e-mail é cassiadarling@gmail.com. ORCID: https://orcid. org/0000-0001-8134-1357.
} 
slave narrative. We argue that the link between the neo-slave narrative and the archive is both concrete and productive, given that it foregrounds non-sanctioned archives as counternarratives to the historical archive (mainly, but not exclusively, that of slavery), through the articulation of history and both personal and collective memory - calling to question, in this way, colonizing documented history and its official guardians.

Keywords: Gloria Naylor; Counterdiscursive Archives; Memory; Neoslave Narratives 
Whether as notion, impression, concept or anti-concept, the image of the archive is a useful focal point for bringing together issues of representation, interpretation and reason with questions of identity, evidence and authenticity.

Thomas Osborne (1999, p. 51)

In the end, what we hear is not, perhaps, the lost alterity; above all, what we find in the archive is ourselves. Harriet Bradley (1999, p. 119)

A presença do arquivo nas diferentes áreas de estudo, entre elas história, antropologia, artes, sociologia e medicina, é indiscutível, uma vez que se configura em uma das grandes ferramentas de pesquisa para estas áreas: “(...) o arquivo serve às disciplinas humanas assim como o laboratório serve às ciências. Tanto um como o outro são lugares de produção de conhecimento" (MANOFF, 2004, p.13, trad. livre). Que possível confluência haveria entre este conceito e um romance literário? Uma confluência digna de nota, e que tem se mostrado produtiva nos estudos literários e culturais, é a da representação literária e processos mnemônicos complexos (sobretudo os que revisitam arquivos de experiências traumáticas coletivas, como a escravidão, a colonização e as guerras), que oscilam entre os atos de relembrar e esquecer. Embora memória e arquivo sejam distintos - posto que, como lembra Derrida (2001), "não há arquivo sem exterior" (p. 22), e como nos adverte Nora (1993, p. 15), o que chamamos de memória, na contemporaneidade, é, na verdade, o "estoque material daquilo que nos é impossível lembrar" -, é exatamente através da preocupação com a forma como têm sido produzidos e registrados os arquivos que podem ser discutidas e problematizadas as interferências na memória coletiva de determinada comunidade. Assim, para Derrida (2001), o arquivo é sempre vinculado ao poder, que determina "a participação e o acesso ao arquivo, à sua constituição e à sua interpretação" (p. 16, N.1).

Arkhê, lembremos, designa ao mesmo tempo o começo e o comando. Este nome coordena aparentemente dois princípios em um: o princípio da natureza ou da história, ali onde as coisas começam [...] -, mas também o princípio da lei ali onde se exerce a autoridade, a ordem social, nesse lugar a partir do qual a ordem é dada [...]. (DERRIDA, 2001, p.11, grifos do autor)

Derrida aponta ainda para dois outros termos ligados a arkhê: arkhêion - a residência dos magistrados, local onde os documentos oficiais (como as leis) eram guardados; e archon, o magistrado, aquele que detinha o poder arcôntico, de "procedimento e precedência", na interpretação das leis. Derrida define, assim, o surgimento dos arquivos atrelando-o ao caráter inegavelmente político que os permeia: "Para serem assim guardados, [...] eram necessários ao mesmo tempo um guardião e uma localização.[...] Foi assim, nesta domiciliação, nesta obtenção consensual de domícilio, que os arquivos nasceram. [...]" (DERRIDA, 2001, p. 13).

$\mathrm{Na}$ discussão que se segue, do romance Linden Hills, da escritora estadunidense Gloria Naylor, propomos investigar forma(s) através das quais 
obras de autores afro-descendentes contemporâneos suplementam o arquivo histórico - sobretudo o da escravidão -, por meio da articulação da história com a memória, pessoal e coletiva. Cabe dialogar com as palavras da socióloga Harriet Bradley (1999, p.108-109), quando ela faz a ressalva de que (não obstante as problematizações esboçadas acima) o arquivo, seja ele sancionado ou não, encontra-se atrelado à memória:

O arquivo é um repositório de memórias: individuais e coletivas, oficiais e não oficiais, lícitas e ilícitas, legitimadoras e subversivas. E, com base em tais memórias, nós lutamos, ainda que parcialmente e sem sucesso, para reconstruir, restaurar e recuperar o passado, para apresentar e reapresentar histórias do passado [ ]. (trad. livre, grifos nossos)

Pretendemos assinalar, em nossa leitura de Linden Hills, manifestações absolutamente concretas do arquivo sob diferentes formas não sancionadas como diários, cartas receitas e, inclusive, registros orais. Vale ressaltar que tais formas arquivais não-sancionadas encontram-se em contraposição ao poder do arconte derridiano, que está fundamentado sobre a autoridade de consignação ("reunião"), concentrando também as funções de "unificação, identificação e classificação" (DERRIDA, 2001, p.13-14). Cabe assinalar, contudo - seguindo o próprio Derrida -, que, se não há arquivo sem arconte, não há arquivo sem apagamentos, recalques. Assim, não há arquivo sem o que o filósofo denominou "mal de arquivo", posto que o mesmo é necessariamente lacunar e sintomático, perpassado pelo esquecimento (proposital ou recalcado, sintomático):

O arquivo é, pois, o lugar da gestão da memória, mas também o campo do esquecimento. Em âmbito governamental, em política, por exemplo, há uma biopolítica (para usar uma expressão cara à temática de Foucault) do esquecimento e apagamento proposital dos traços, das informações, das impressões. Lembrar e esquecer, tal é a ambivalência do movimento do arquivo. Isso vale para a realidade e para a ficção. No romance 1984, de Orwell, quem não se lembra do Ministério da Verdade, no qual Winston, o protagonista, tem por tarefa falsificar e apagar documentos, impressões que comprometessem a "verdade" do Partido; e o "Buraco da memória" como incinerador de arquivos? (SOLIS, 2014, p. 382)

O neo-arquivo e as neonarrativas de escravidão

Um dos mais dolorosos arquivos da humanidade é, inegavelmente, o da escravidão, registrado pela história oficial e, mais contemporaneamente, por (contra)narrativas pós-coloniais. Em Linden Hills, obra que lida com a escravidão e suas consequências na vida do afro-descendente na sociedade estadunidense, a presença do arquivo é marcante, multifacetada e serve, exatamente como dito por Bradley (1999), para (re)apresentar o passado, discuti-lo e ressignificá-lo. A memória desse episódio tenebroso, que ainda assombra, tem sido registrada ao longo do tempo nas diferentes artes, como a pintura, escultura, fotografia 
e filmografia - e aponta para a constatação de que, seja apagada pelos agentes da história oficial, ou recalcada pelo trauma da subalternidade, basta acionar o arquivo para que ela venha à tona, em suas formas multifacetadas. Na literatura, os registros têm sido variados: poemas, ensaios, peças teatrais, romances e contranarrativas de viagem. Seus autores, em sua maioria pós-coloniais, contribuíram para a construção do neo-arquivo (neo-archive), termo proposto por Erica Johnson (2014) no artigo intitulado "Building the Neo-Archive: Dionne Brand's A Map to the Door of No Return". Inspirada pela presença marcante do arquivo no livro de Brand, ${ }^{1}$ Johnson faz um interessante contraponto entre o arquivo colonial (britânico e francês) e o neo-arquivo, apontando que a voz do escravo não é ouvida no arquivo colonial; não há informações ou reflexões sobre sua penosa experiência. Segundo a autora, no portal dos arquivos nacionais britânicos disponíveis na internet é possível se ler a ressalva de que

a maioria de seu material ecoa a experiência e pensamentos daqueles que perpetuam a instituição. [...] A maioria dos registros sobre o comércio de escravos é escrita do ponto de vista daqueles que controlam a atividade, e muito pouca informação sobre os escravos africanos está disponível. (JOHNSON, 2014, p.155, trad. livre)

Em resposta à violência epistêmica do arquivo colonial, a literatura póscolonial vem confrontando a história veiculada pelos registros britânicos, franceses e europeus em geral, por meio das obras de renomados autores ${ }^{2}$ que exploram fatos históricos como a travessia da passagem do meio - Middle Passage - e o genocídio no Haiti, por exemplo, mesclando-os com ficção. Para Johnson (2014, p. 157), este tipo de produção literária opera em conjunto com pesquisas de historiadores, formando o que ela chama de neo-arquivo²:

a ficção que cria a história em face de sua ausência. Ao contrário de historiadores, escritores de ficção podem mergulhar no tempo condicional [...] e fundi-lo com o presente por meio de explorações poéticas das lacunas nos arquivos. (trad. livre)

Tomamos por empréstimo o conceito de Johnson, estendendo-o à escritora afro-americana Gloria Naylor, em cuja obra percebemos a mesma proposta de questionamento dos arquivos coloniais, com sua produção que dá voz ao Outro apagado pelo arquivo oficial. Nossa leitura de Linden Hills articula, por sua vez, o conceito de neo-arquivo com a chamada neonarrativa de escravidão, que teve sua origem nas narrativas de escravidão surgidas com a ascensão dos movimentos abolicionistas no final do século XVIII. Por meio de narrativas eminentemente políticas, autores afro-descendentes começaram a questionar o sistema escravocrata, construindo um arquivo que apresentava o negro com uma imagem diferente daquela caricatural do escravo fujão e mau (EATON, 2012). Apesar de ter surgido como uma importante produção no cenário literário, esse gênero foi negligenciado e reputado como de pouca importância 
por vários anos, uma vez que sua credibilidade e autenticidade eram bastante questionadas (o que não causa espanto, já que seus autores eram ex-escravos). Contudo, em meados do século XX, na efervescência do Movimento pelos Direitos Civis, deu-se a retomada formal da tradição das narrativas de escravidão, desta vez com uma nova roupagem - a neonarrativa de escravidão - que, segundo Beaulieu (1999 apud LYSIK, 2004, p. 17),

[tornou-se] uma das mais importantes contribuições para a literatura americana do século XX. Autores afro-americanos contemporâneos reconhecem a vitalidade do gênero, e em seus romances de ficção ou de ficção parcial, fazem explícitas referências à escravidão e ao destino dos escravos. (trad. livre)

Enquanto as narrativas de escravidão clamam pela abolição, as neonarrativas põem em relevo o legado do sistema sobre os afrodescendentes, já que a abolição da escravatura não significa, absolutamente, o cancelamento de seus efeitos. Como observado por Hawkins (2012, p.1) busca-se "direcionar o futuro, já que o passado não pode ser desfeito" (trad. livre). Para esta crítica, a escravidão foi um tema bastante presente em diversos momentos históricos dos EUA, desde o início do comércio no Atlântico, passando pela Guerra Civil, o Harlem Renaissance, ${ }^{4}$ e os anos 1930-1940. Contudo, o auge das discussões começa justamente com o surgimento das neonarrativas, ${ }^{5}$ nos anos 1960. Seus autores, grandemente influenciados pela atmosfera de mudança deste período, revisitavam o passado com suas obras, "não com uma nostalgia romântica", mas para apresentar "uma análise crítica da história, cujo objetivo era incendiar a resistência política" (HAWKINS, 2012, p. 10-11, trad. livre).

Entendemos que o vínculo da neonarrativa de escravidão com o arquivo é bastante concreto e produtivo, pois traz a lume os eventos associados à escravidão e seu legado, fazendo conhecidas algumas vozes outrora silenciadas, que (re) contam histórias um dia mal contadas, questionando, desta forma, a história documentada pelo opressor. Linden Hills também propõe esta visita ao passado, através da escavação do palimpsesto de memórias individuais e coletivas outrora esquecidas, não identificadas, estabelecendo, assim, seu parentesco com as neonarrativas.

Os poetas, o historiador a mulher: suburbia contradiscursiva e a topografia da memória recalcada em Linden Hills

My memory stammers; but my soul is a witness. James Baldwin (1985, p. xiii)

Aparentemente, Linden Hills apresenta um enredo bastante comum: o romance narra alguns eventos que se desenrolam nos seis dias que antecedem o Natal, na vida dos moradores de um determinado suburb estadunidense. Entretanto, Gloria Naylor quebra o paradigma dos suburbs ${ }^{6}$ americanos ao fazer de Linden Hills uma comunidade de negros abastados, e não de brancos da classe média/alta. 
Embora o suburb estadunidense tivesse tido o que podemos denominar seu primeiro boom, na década de 1920, quando grande parte da população fugia das cidades industriais para viver em seus arredores, foi após a Segunda Guerra que os suburbs foram criados para serem a manifestação do American way of life. Em 1947, quando Abraham Levitt e seus dois filhos William e Alfred projetaram o que viria a ser o protótipo do suburb dos fifties (Levittown), transformando o que outrora fora uma paisagem agrícola em uma comunidade planejada, não podiam imaginar que os suburbs se tornariam icônicos. A fusão de espaço e identidade reforçou o mito da família saudável, padrão, vivendo em uma nação saudável, normal (cf. WRIGHT, 1983). Mas, na verdade, essa esfera de isolamento e domesticidade separava tais comunidades do resto da nação e, ademais, por debaixo da aparente homogeneidade, existia uma diversidade étnico-racial que resultava em conflitos. Em meados do século XX, a imagem tradicional da suburbia começou a sofrer mudanças e uma releitura crítica, não somente no espaço acadêmico como na literatura ${ }^{7}$ e cultura popular, sobretudo no cinema. ${ }^{8}$

Linden Hills fora criada por um negro para negros. O suburb imaginado por Gloria Naylor rompe com a hegemonia da comunidade branca, já que, ali, negros abastados têm a oportunidade de 'chegar lá e provar do status que morar em tal ambiente confere aos brancos. Mas, sua origem, narrada no início do romance, é bem distinta de sua opulência atual. Linden Hills era um lugar pouco valorizado - "só o lado norte, sem valor, de uma rica planície"9 (NAYLOR, 1985, p.1, trad. livre) -, adquirido por um negro, o primeiro da 'dinastia' Nedeed, com o dinheiro da venda de sua mulher e filhos como escravos. Depois, devido a uma contenda judicial com brancos pela posse das terras, ele decide começar a vender propriedades nas terras para negros - a quem ele concedia mil anos e um dia de locação. Posteriores negócios (como a venda dessas propriedades) deveriam ser feitos apenas entre negros (p. 7). Assim, desde seu início, Linden Hills fora destinado a pertencer aos negros; a ser um espaço de confronto 'com o deus branco', uma forma de assertividade da negritude (cf. ENGLES, 2009, p. 664). Este destino não seria impedido pela resistência e deboche dos brancos:

Certamente, eles o achavam um tolo - [...] Bem, ele iria mostrar a eles. Este pedaço de terra era dele. [...] Ele poderia ser uma mosca em um unguento, uma mancha em um lençol alvejado, e Linden Hills mostraria isto. Ele dera a seu povo uma das mais caras propriedades no país [...]. $(\text { NAYLOR, 1985, p. 8, grifos nossos) })^{10}$

É relevante observar que a comunidade negra de Linden Hills suspeitava das intenções de Nedeed: "Por que de repente ele estava sendo tão bom com os negros, se seu pai fora um traficante de escravos?” (NAYLOR, 1985, p. 8, trad. livre $)^{11}$, mas a ambição de viver um 'sonho branco' abafava sua desconfiança.

Linden Hills, "a joia de ébano" (NAYLOR, 1985, p. 9), tem uma geografia diferenciada: apenas oito ruas residenciais circulares (começando pela Eighth Crescent Drive, chegando à First Crescent), que descem até o número 999, residência de Luther Nedeed (o último de sua dinastia, atual 'dono' da 
comunidade), considerado o local mais nobre da comunidade. Paradoxalmente, ali, ao lado de sua residência, ficava o cemitério da cidade e, em sua própria casa, o necrotério. O primeiro Nedeed, um visionário, discernia com clareza o valor de sua empreitada comercial: "Basta sentar-se aqui e eles lhes farão rico por meio das duas coisas que terão que fazer: viver (morar) e morrer" (NAYLOR, 1985, p. 6). ${ }^{12}$

Lançando mão da estratégia de Signifyin(g) (cf. GATES, 1988), ${ }^{13}$ Gloria Naylor, cria uma comunidade que pode ser lida como alegoria, ${ }^{14}$ a começar pela configuração do lugar, que tem sido interpretada (e reconhecida pela autora) como uma clara referência ao Inferno, parte da obra prima de Dante Alighieri, $A$ Divina Comédia. ${ }^{15}$ Mas o projeto de Naylor transcende a mera apropriação e a autora subverte a hegemonia branca, ao fazer de Linden Hills uma comunidade de negros abastados que 'chegaram lá, e viveram seus próprios infernos. Além disso, ao contrário da maioria dos lugares, ali, quanto mais abaixo geograficamente alguém estabelecesse sua casa, mais status teria; ou seja, para 'subir', em Linden Hills, é, paradoxalmente, necessário descer.

À medida que a história se desenrola, a verdadeira face da comunidade - e de seus habitantes - vai sendo revelada. Arquivos coletivos e individuais são abertos e o leitor tem acesso a dramas existenciais que o dinheiro e o glamour ocultavam. Mesmo sem perceber, a maioria dos moradores de Linden Hills negocia valores, honra e ética para alcançar seus objetivos; alguns abrem mão de sua própria felicidade em troca de uma vida superficial e infeliz. O preço é alto, mas eles só o percebem - quando percebem - no momento em que alcançam o tão sonhado prestígio. De maneira geral, o homem, sobretudo o ocidental ou ocidentalizado, é atraído pela ideia de sucesso e, em algumas sociedades, esta atração/busca chega a ser um traço cultural. Para McKeever (2007, p. 1), a sociedade estadunidense é obcecada pela ideia de sucesso, definido não exatamente pelo indivíduo, mas pelo olhar do outro sobre ele. Em se tratando de minorias, como o negro, por exemplo, este olhar é ainda mais contundente, o que torna sua corrida de vida ainda mais feroz. Os moradores de Linden Hills vivenciam angústias e frustrações silenciosas que os encerram em bueiros existenciais, alguns dos quais nunca serão abertos.

Nesta notável (neo)narrativa, Gloria Naylor abre arquivos que expõem algumas faces do legado do sistema escravagista, tão latentes naquela comunidade, mas tão enfaticamente evitadas. Selecionamos, para breve análise, quatro personagens exponenciais no que tange ao arquivo: a dupla de poetas de rua Willie e Lester; Dr. Braithwaite, o historiador que tudo vê, e Willa, mulher de Luther Nedeed, o 'dono' da comunidade. Arcontes oficiais ou não, é por meio deles que a face oculta da comunidade é descortinada ao leitor.

\section{Os poetas de rua: arcontes com street cred $^{16}$}

Às vésperas do Natal, Lester e Willie, jovens, poetas de rua desempregados, resolvem ganhar dinheiro fazendo serviços domésticos para os moradores da comunidade. Lester é morador do local, mas a posição de sua casa (localizada na 
Eighth Crescent Drive, a rua mais alta, distante da residência dos Nedeeds) não confere à sua família um status elevado. Ao contrário da inquietação que isto gera em sua mãe e irmã, isto não faz a menor diferença para o rapaz, que intentava ser um poeta e defensor da causa negra, como Malcom X, "seu personagem favorito da história"17 (NAYLOR, 1985, p.26). Seu amigo Willie, apelidado 'White', por ser "tão preto, que se escurecesse um tom, se tornaria branco"18 (NAYLOR, 1985, p. 24), de família humilde e desestruturada, mora em Putney Wayne, uma comunidade periférica, mal-afamada, e evitada pelos moradores de Linden Hills. À medida que os jovens descem as ruas de Linden Hills, assim como Virgílio e Dante, na Divina Comédia, eles adentram o Inferno: ao terem acesso à intimidade dos moradores abastados, testemunham mazelas antes ocultas, tornando-se o que entendemos como arcontes mundanos, que abrem para o leitor uma série de arquivos pessoais e coletivos - centros de interpretação (cf. OSBORNE, 1999, p. 52) - a partir dos quais eles releem a comunidade. No artigo "The seductions of the archive: Voices lost and found", Harriet Bradley cita a autora irlandesa Ciaran Carson, que propõe que a cidade (no caso, Belfast) é, em si, um arquivo da memória, a partir do qual o narrador pode pinçar objetos, símbolos e traços infinitos, lançando mão do "arquivo abundante de seu olhar interior" (CARSON, 1997, p. 80, apud BRADLEY, 1999, p. 108). De forma análoga, ao percorrerem as ruas de Linden Hills, Willie e Lester vão juntando objetos, símbolos e traços, que se transformam na poesia que jamais é escrita, mas composta e guardada em suas memórias, gerando um novo arquivo. Entendemos, dessa forma, que personagens podem ser o próprio arquivo, carregando em si histórias individuais e coletivas, presentes e passadas.

Em seu primeiro trabalho, no casamento do advogado Winston Alcott, os jovens ficam perplexos com tamanha pompa; a ostentação do lugar e a imponência dos convidados, todos negros, servidos por garçons brancos, é lamentável para Lester; já Willie sente certo contentamento por ver que há negros que alcançaram aquele padrão de vida - mas, ao mesmo tempo, é acometido de grande inquietação, porque discerne a falta de espontaneidade no ambiente. Mais sensível que o amigo, Willie observa que os negros ali "teriam medo de suar"19 (NAYLOR, 1985, p. 83). É ele que também percebe a tristeza do noivo, jovem advogado homossexual, que abre mão do relacionamento com seu parceiro, em parte devido à imposição de seu pai, em parte por causa de sua própria ambição, e se casa com uma mulher.

Em outro momento, os jovens prestam serviço a Xavier Donnell, executivo ambicioso, que tem um romance não assumido com Roxanne (irmã de Lester) e prefere a companhia de mulheres brancas em público. Seu 'mentor' é Maxwell, colega de trabalho, alto executivo excêntrico, que descobrira que "só poderia dobrar suas chances de chegar em primeiro lugar se não carregasse o peso daqueles miligramas de pigmento em sua pele"20 (NAYLOR, 1985, p. 102, grifos nossos). Para ele, não bastaria apagar alguns traços de suas origens; o que ele intenta é anular, o máximo possível, sua própria negritude.

Os jovens passam por outras casas, e vivenciam situações que os surpreendem, mas que abrem seus olhos às verdades individuais e sociais ocultas. 
Eles testemunham tragédias, como o incêndio na casa dos Nedeed, que põe fim àquela dinastia, assim como o suicídio da jovem e bela Laurel, a mais alta executiva da IBM, uma "amazona" (NAYLOR, 1985, 228), mas absolutamente frustrada em sua vida familiar. Em meio ao tumulto causado por sua morte, eles conhecem o dr. Daniel Braithwaite, vizinho da moça, renomado professor de História e autor de registros da história da comunidade. Ao contrário de Willie e Lester, arcontes de facto, cujas andanças os levaram ao encontro de arquivos pessoais e coletivos, mas cujo testemunho provavelmente não seria reconhecido, o historiador recebe da própria família Nedeed a incumbência de registrar as histórias de Linden Hills, sendo, assim, o arconte por excelência, de jure.

\section{O arconte legitimado e seus arquivos 'imparciais'}

Vimos que Derrida inicia sua conceituação do arquivo refletindo sobre o mesmo como um lugar concreto, um domicílio, uma residência - por exemplo, bibliotecas, centros de armazenamento de dados, arquivos públicos e, mais contemporaneamente, portais na Internet. Osborne (1999), em seu artigo "The Ordinariness of the Archive", sugere que o arquivo moderno constrói-se sobre três pilares: um princípio de publicidade, por meio do qual a informação é tornada disponível a algum tipo de público em particular; um princípio de singularidade, de acordo com o qual a razão arquivística foca algum detalhe em particular; e um princípio mundano, cujo enfoque privilegia a dimensão do cotidiano (p. 51). O autor propõe, assim, que a produtividade do arquivo é sua elasticidade - perpassando, mas indo além da referência literal, saindo do plano físico para um plano mais ideal da experiência subjetiva ou do sujeito cognoscente, autônomo: o agente do arquivo, seu intérprete, e sua história (p. 52). Lembrando que o intérprete do arquivo não é o mesmo que seu guardião, Osborne faz menção a historiadores e pesquisadores da academia como intérpretes do arquivo (e certamente o somos, como críticos literários ou da cultura). Indo um pouco mais além, gostaríamos de sugerir que, aqui, os intérpretes dos arquivos secretos da comunidade, ao descerem ao 'inferno' (o âmago dos segredos bem guardados, a casa de Nedeed), tornam-se novos 'arcontes'. Osborne (1999, p. 54) observa que, assim como o trabalho de campo do antropólogo representa verdade e conhecimento, concedendo-lhe certa autoridade, o arquivo confere direitos similares àqueles - sejam quem forem - que buscam gerar credibilidade nele baseada (grifos nossos). Ele acrescenta que a pessoa que fala a partir do arquivo medeia entre seus segredos e obscuridades e um público em particular (OSBORNE, 1999, p. 54) - no caso, as novas gerações afro-americanas que virão após o fim da dinastia dos Nedeeds (e possíveis leitores afrodescendentes).

Para alguns teóricos, o arquivo está indissoluvelmente ligado às questões de poder. Conforme já vimos, Derrida (2001) atrela o conceito tanto a começo quanto a comando. Para ele, o poder arcôntico, que está fundamentado sobre a autoridade de consignação ("reunião"), "concentra também as funções de unificação, identificação e classificação” (DERRIDA, 2001, p.13-14). Foucault (1972), por sua 
vez, entende que as relações de poder que permeiam o arquivo são claras, já que há um filtro que limita o que pode ou não ser veiculado. Assim, a natureza do arquivo "é moldada por forças sociais, políticas e [até] tecnológicas" (MANOFF, 2004, p. 12, trad. livre). Em Linden Hills, Gloria Naylor apresenta o arquivo sob diferentes enfoques e, no personagem do Dr. Braithwaite, o historiador/arquivista, o leitor encontra o arconte autorizado a consignar fatos e documentos, e seu arquivo "totalitário" (OSBORNE, 1999, p. 57) está guardado no arkheion, que, no romance, é a sua própria casa. O personagem teve seus estudos patrocinados pelo avô de Luther e, quando volta a Linden Hills como historiador, recebe a incumbência de arquivar a história da comunidade, e é o único a ter acesso aos registros da família - relatórios, documentos oficiais e até notas de venda, datadas de 1820 “informações de valor inestimável”21 (NAYLOR, 1985, p. 259).

Vale assinalar que sua casa, um depósito de preciosidades acadêmicoliterárias - inclusive um exemplar de The Philadelphia Negro, ${ }^{22}$ assinado pelo próprio autor - está localizada em um lugar privilegiado, que permite a ele a observação contínua de tudo e todos na comunidade; nada escapa a seu olhar. Assim, ele está em posição - figurada e literalmente - de arconte, para criar seus arquivos. Sua coleção de doze livros sobre Linden Hills (onze completos e o último em andamento) lhe rendera inclusive uma possibilidade de indicação ao prêmio Nobel (NAYLOR, 1985, p. 261). Entretanto, ao escrever o sexto volume, o historiador percebe uma mudança nos objetivos da população local e, para seu desapontamento, entende que seu trabalho era um "relatório sobre pessoas perdidas", em sua busca por poder e prestígio social (NAYLOR, 1985, p. 261). Lester o confronta sobre o fato de ele não usar seu trabalho para "salvar vidas", como a de Laurel, que ele sabia estar com sérios problemas existenciais. Distanciamento é a justificativa do doutor: ele apenas 'estuda' as pessoas e, para isso, "andou em meio a elas, comeu com elas, riu com elas, ${ }^{23}$ mas para atingir seu objetivo, bem estabelecido desde o início, ele deveria evitar "todo e qualquer envolvimento"24 (NAYLOR, 1985, p. 264). Para Bradley (1999), esse tipo de postura é uma falácia; a neutralidade é utópica, pois ao escrever a história, o pesquisador a reescreve, recriando o passado "em novos formatos" (BRADLEY, 1999, p. 109, trad. livre). Schwartz (2006) dialoga com Bradley, ao defender que "arquivistas continuamente reformulam, reinterpretam e reinventam o arquivo, [o que] "representa um enorme poder sobre memória e identidade [...]" (SCHWARTZ, 2006, p. 3, trad. livre).

\section{Mas elas registraram tudo: os arquivos das mulheres invisíveis}

O projeto de criar um sonho americano negro precisava ser bastante audacioso e, de fato, o fora. Os Nedeeds controlavam cada detalhe afeto à comunidade para que tudo fosse perfeito e Luther, o último representante da dinastia, leva isto às últimas instâncias, chegando mesmo ao ponto de manipular - sutilmente ou não - vidas e rumos. Organizada e regida por mão forte há gerações, a comunidade de Linden Hills parece habitar o panóptico de Bentham (1787). Para tomarmos 
emprestada a descrição de Miran Božovič (cf. BENTHAM, 1995, quarta capa), o panóptico é uma "cela genial e cruel na qual os sujeitos colaboram com sua própria submissão [...] [produzindo] não apenas uma prisão, mas também um deus dentro dela" (trad. livre, grifo nosso). O grande deus abstrato em Linden Hills é o poder, e sua personificação, Luther Nedeed, um homem de aparência feia e sombria, cujo domínio transcende a cor, tornando-o ameaçador tanto para negros quanto para brancos (NAYLOR, 1985, p. 3).

A opressão exercida por Luther é patente também em sua vida familiar, padrão vigente em toda a dinastia Nedeed. Seus ancestrais tratavam suas mulheres como meras reprodutoras e, uma vez cumprida sua 'missão' de gerar um herdeiro, elas caíam, ou eram lançadas no ostracismo. No caso do último Luther Nedeed, a situação é ainda mais grave, pois ele literalmente aprisiona sua mulher e filho no porão de sua casa. Conquanto muito parecida com o pai fisicamente, a criança tem um tom de pele mais claro, o que leva o marido a desconfiar de traição e executar seu juízo. No confinamento, o menino, que já estava doente, acaba morrendo. Passado o primeiro momento de sua enorme dor, quando quase enlouquece, Willa, a esposa, começa a se recompor e passa a viver seus dias lendo as memórias das Senhoras Nedeed, suas antecessoras, que ela encontra no porão. E é por meio do mergulho nestes arquivos pessoais, íntimos, esquecidos e não-sancionados, que ela volta à vida e executa sua última e, talvez, mais importante missão.

O encontro de Willa com os arquivos de suas antecessoras foi casual e em meio a circunstâncias trágicas, fruto de um caos existencial já sinalizado, mas não percebido por ela. Assim como as outras mulheres dos Nedeeds, ela fora levada para Linden Hills com um propósito muito claro: ser a geradora do futuro herdeiro daquele império, o que não significaria, absolutamente, uma vida feliz e realizada, assim como não significou para as outras. Uma vez que sua missão tivesse sido concluída, Willa também seria anulada, algo que ela só veio a entender ao acessar as memórias da angústia silenciosa - e silenciada - de suas antecessoras. Ao confrontar a realidade, até então oculta, naqueles arquivos pessoais, a mulher acaba tendo um encontro com sua própria vida e com sua invisibilidade.

Seu casamento com Luther não fora baseado em amor, mas em uma 'escolha' meticulosamente planejada por ele; assim como seus ancestrais, ele precisava da esposa perfeita para levar para Tupelo Drive. Ele, que se vê como ótimo marido, oferece à esposa uma vida 'perfeita', um nome, uma bela casa e conforto: “[...] seis linhas de crédito, sem nunca lhe perguntar o que ela comprara e por quê. E pedira a ela tão pouco em troca. [...] apenas que o respeitasse e cuidasse das rotinas da casa" (NAYLOR, 1985, p. 68, grifos nossos). ${ }^{25}$ Entretanto, seus planos são frustrados pois Willa gera um filho que tem todos os traços do pai, à exceção da cor, pois o menino é "branco", o que não surpreende, visto que a mulher tem um tom de pele "um pouco acima do pálido" (NAYLOR, 1985, p. 18). Contudo, para ele, a tonalidade da criança é um espectro que assombra seu império, erguido há cinco gerações por seus ancestrais. Assim, o homem decide punir a 'infidelidade' da esposa e a encarcera - juntamente com o filho - no porão de 
sua casa, anteriormente uma sala de necrotério, local de trabalho dos homens da família (dona do único cemitério local). O menino, que estava doente, não resiste e vem a falecer, o que leva Willa à beira da loucura.

Ao buscar um pano para enrolar o corpo do filho, ela encontra o primeiro arquivo: uma Bíblia, datada de 1837, que pertencera à Luwana Packerville, a primeira das senhoras Nedeed. A mulher, uma escrava comprada - mas não alforriada - pelo marido, o tataravô de Luther, usava as páginas do livro para registrar seu sofrimento. Afastada do filho e da convivência familiar, Luwana passa a escrever suas misérias para atenuar sua dor. Ela se frustra profundamente ao entender que seu casamento, visto por ela como uma libertação, tinha sido, efetivamente, uma troca de donos: "Oh, Amado Salvador, será que eu troquei um senhor por outro? Será que os inocentes rabiscos que fiz somente para esconderme do desprezo de um marido são agora o diário de uma escrava?" (NAYLOR, 1985, p. 117). ${ }^{26}$ A descoberta deste primeiro arquivo é um choque para Willa, não apenas pela revelação do conflito familiar, como também pela referência explícita à escravidão, eterno fantasma para o afrodescendente. Para espanto ainda maior de Willa, ela encontra quatro cartas, escritas por Luwana para si própria, nas quais ela narra a evolução de seu desespero, pois, à medida que o filho cresce, ele se aproxima mais do pai, e se afasta cada vez mais dela.

Crescentemente mais confinada à sua solidão 'em família', Luwana escreve para 'sua irmã', para quem conta suas mazelas e de quem, a princípio, recebe até 'conselhos. Em sua última carta, ela narra a quantidade exata de vezes "que abrira a boca para falar em um ano inteiro: 332 para responder aos seus 'bom dia' e 333 para fazer o mesmo à noite". O detalhe estarrecedor é que, para não se perder nas contas, Lwuana marcara - literalmente - cada uma destas vezes em seu próprio corpo, com um alfinete de prata "a fim de que não houvesse o perigo de apagá-las durante o banho" (NAYLOR, 1985, p.124, trad. livre). Aqui, é clara a referência a mais uma página tenebrosa do arquivo da escravidão, a da marcação de escravos, feita com ferros em brasa, anavalhamento do corpo ou outros tipos de mutilações, além de uma série de diferentes castigos físicos, de sadismo inominável. ${ }^{27}$

Ao ler as "memórias enterradas" de Lwuana, Willa começa a ter um vislumbre de sua situação e se questiona sobre seu casamento. A escavação dos arquivos da primeira senhora Nedeed aciona em Willa "um sentido de pertencimento" (BRADLEY, 1999, p.110) e identificação, e ela sente que precisava continuar ouvindo a voz de Lwuana, que ecoara tão profundamente em sua alma; assim, Willa sai da posição de leitora por acaso e, em seu confinamento naquele porão, assume a de arqueóloga,

[...] que busca destravar os significados guardados, permitindo que as vozes do passado falem, especialmente as vozes daqueles convencionalmente silenciados em discursos oficiais, as famosas vozes do Outro. ${ }^{28}[\ldots]$ determinada a fazer ouvidos os emudecidos; mas ele [o arqueólogo] o faz engajando-se pessoal e diretamente no diálogo com eles. Ele não apenas os ouve falar, mas permite que eles falem! (BRADLEY, 1999, p. 114, trad. livre, grifo da autora) 
Derrida (2001, p. 35), ao discutir a lógica e a semântica do arquivo, percebe-o como uma infinidade de camadas superpostas. De forma análoga, constatamos uma superposição de arquivos das mulheres de Nedeed. Willa, uma arconte por acaso, tem em suas mãos um palimpsesto biográfico e histórico, a partir do qual ela começa a fazer sentido de sua própria narrativa biográfica e histórica, que deve ser decifrada, recomposta, (res)significada. A metáfora da escavação nos remete, por sua vez, a Benjamin (2000, p. 239-240), que escreveu: "quem pretende se aproximar do próprio passado soterrado deve agir como um homem (sic) que escava", pois "[...] um bom relatório arqueológico deve não apenas indicar as camadas das quais se originam seus achados, mas também, antes de tudo, aquelas outras que foram atravessadas anteriormente."

Em sua busca por mais registros de Lwuana, Willa encontra receitas culinárias, datadas de 1892, que pertenceram a uma determinada Evelyn Creton Nedeed. Sem saber, ela estava prestes a abrir mais um arquivo sombrio da família de Luther. A princípio, Willa se aborrece, por achar que eram apenas informações sem importância sobre uma mulher que gostava de cozinhar. Entretanto, à medida que vai lendo as anotações, percebe que aquelas não eram simples receitas, mas registros de uma "mulher [que] cozinhava como se estivesse possuída", e que anotava tudo - inclusive datas de compra e utilização dos ingredientes "com uma precisão fanática" (NAYLOR, 1985, p.140). A aparente simplicidade daqueles arquivos ocultava uma grande revelação, confirmando o que postula Osborne (1999, p.61, trad. livre) ao sugerir que o lugar de poder do arquivo pode ser mais simples do que imaginamos, não estando vinculado a "soberanias e políticas, ou ao âmbito de teorias dominantes, mas [oculto] nos interstícios da vida, onde o corriqueiro e o cotidiano acontecem".

O que Willa descobre em seu mergulho nestes arquivos não é o melhor de si mesma; ao contrário, ela percebe que seu relacionamento com Luther nunca fora 'natural', e que sua letargia e falta de percepção a haviam levado até onde ela estava, literalmente. Entretanto, ao contrário de Lwuana e Evelyn, ela não enlouquece, mas reescreve o arquivo de experiências passadas, a partir do "cemitério povoado de vidas e memórias" (SOLIS, 2014, p. 385) que é o porão onde se encontra. A espectralidade desses arquivos é tão pungente, e o peso de suas revelações tão asfixiante, que Willa resolve se livrar do sufocante arquivo das vidas "distorcidas e tristes" (NAYLOR, 1985) de suas antecessoras. Ao começar a destruir roupas, chapéus, flores secas, a personagem depara-se com um álbum de fotografias, que, a princípio, também intenta eliminar. Porém, os olhos de uma mulher em uma foto atraem tanto sua atenção, que Willa, mais uma vez, decide explorar aquele que seria mais um arquivo potencialmente revelador - e bizarro - da família Nedeed. Fotos - imagens como arquivos - segundo Sontag (1973 apud HIRSCH ${ }^{29}$ 2001, p. 6) têm um efeito incontestavelmente impactante: "Fotografias chocam na medida que revelam algo inusitado...Uma vez que tenha visto tais imagens, a pessoa toma uma estrada para ver mais - e mais. Imagens paralisam. Imagens anestesiam" (trad. livre). Willa certamente "tomou a estrada para ver mais”; entretanto, o impacto não a paralisa: ao contrário, o mergulho 
no passado descortina sua verdadeira condição no presente. Em sua escavação incessante dessas memórias, entendemos que Willa se tornou uma pesquisadora que 'contraiu' o mal de arquivo ${ }^{30}$ (DERRIDA, 2001) - ou seja, o desejo de localizar, ou possuir, o arkhê, ou começo das coisas. Em sua caminhada, Derrida (2001) postula que o arquivo não tem começo nem fim; é, antes, inacabado, aberto possuindo, portanto, arquivos por vir (as neonarrativas, por assim dizer).

As fotos iniciais revelam uma mulher sorridente e feliz ao lado de um marido de expressão taciturna. Há uma cronologia de fatos nas fotografias: o casamento do casal, o nascimento do filho e as diferentes fases de sua vida, registradas até os vinte e um anos do rapaz. Contudo, este que deveria ser apenas mais um registro familiar corriqueiro, aterroriza Willa: ela percebe que, com o passar dos anos, uma sombra projeta-se sobre a figura de Priscilla, que vai sendo literalmente apagada: "Luther: 21 anos. Ela não estava mais registrando o crescimento de uma criança; a única coisa que estava crescendo nestas fotos é sua ausência" "31 (NAYLOR, 1985, p. 208; 209, grifos nossos). Como as demais senhoras Nedeed, incluindo ela própria, Willa entende que tinha apenas servido a um terrível propósito para aquela família e que, uma vez alcançado, ela deveria, como as outras, cair na solidão e esquecimento. Apesar de terrivelmente fraca, dado o tempo de confinamento, e esboroada emocionalmente, ela entende que "poderia reconstruir" (NAYLOR, 1985, p. 268). Assim, aquele porão não seria sua sepultura, mas a incubadora de seu renascimento, através de um devir, de uma neonarrativa para todas as demais mulheres que um dia habitaram o porão. ${ }^{32}$

Em Linden Hills, uma neonarrativa de escravidão de contornos intensos, os temas abrem-se em um leque de infinitas possibilidades de análise em que a escravidão e seu legado ao afrodescendente são desarquivados e confrontam o leitor ao apresentar uma outra face da herança do afro-americano: a tentativa de distanciamento de sua origem - e de sua cor - levada a extremos (até mesmo à morte) por homens e mulheres que, sem perceber, haviam descido ao inferno de sua existência. Seja pelos jovens poetas, despojados e atentos, pelo historiador eficiente e distanciado, ou pela mulher condenada ao porão, o leitor de Linden Hills é apresentado aos mistérios arquivados nas vidas daquele lugar, "onde nada era o que parecia" (NAYLOR, 1985, p. 274).

Notes

1. cf. BRAND, Dionne. A Map to the Door of No Return: Notes to Belonging. Toronto: Vintage Canada, 2001.

2. A título de exemplo, remetemos o leitor para Edwidge Danticat (nascida no Haiti), Fred D’Aguiar (nascido em Londres, de pais naturais da Guiana Inglesa), Caryl Phillips (natural de Saint Kitts) e o dub poet jamaicano Linton Kwesi Johnson (também conhecido como LKJ), único poeta negro a sair publicado na série Penguin Modern Classics.

3. Nesta mesma linha, BUONAIUTO $(2004$, p.11; 12$)$ sugere que uma panorâmica complexa do arquivo da África diaspórica está presente em The Atlantic Sound, de Caryl Phillips (2001), obra que ela chama de crônica histórica.

4. Movimento cultural dos anos 1920 (1918-1930), centrado no Harlem (Nova 
York), que influenciou muitos escritores negros de colônias africanas e do Caribe que viviam em Paris. O filósofo afro-americano Alain LeRoy Locke é considerado um dos grandes divulgadores do movimento.

5. Native Son (Richard Wright, 1940); The Man Who Lived Underground (Richard Wright, 1942); Invisible Man (Ralph Ellison, 1952); Confessions of Nat Turner (William Styron, 1967) e Jubilee (Margaret Walker, 1966) são exemplos de obras que figuram entre as várias produções da época.

6. Optamos pela utilização da palavra inglesa $\operatorname{suburb(s)}$ pelo fato de que, em português, especificamente no Brasil, ela adquiriu uma conotação socialmente pejorativa, já que 'subúrbio' é o local onde, em geral, a população de baixa renda se estabeleceu, sendo, portanto, comumente associado à pobreza. Nos Estados Unidos, entretanto, se deu justamente o contrário: lá, os suburbs se tornaram o locus privilegiado da classe média branca.

7. O conto "Neighbors", de Raymond Carver (1971), vem logo à mente; mas não podemos excluir os contos de John Cheever, que o antecedem, todos críticas explícitas à suburbia.

8. Apenas num rápido brainstorming, vêm à mente filmes como The Graduate (1967, dir. Mike Nichols), Poltergeist (1982, dir. Tobe Hooper), Pleasantville (1998, dir. Gary Ross), e The Stepford Wives (2004, dir. Frank Oz).

9. Todas as citações de Linden Hills são traduções livres do original em inglês.

10. "Sure, they thought him a fool - [...] Well, he would show them. This wedge of earth was his. [...] He could be a fly in an ointment, a spot on a bleached sheet, and Linden Hills would prove it. He had given his people some of the most expensive property in the county [...]".

11. "Why was he up and being so nice to colored folks when his daddy had been a slave dealer $[\ldots]$ ?"

12. "Just sit here and they'll make you a rich man through the two things they'll have to do: live and die".

13. Segundo Gates, é inegável a confrontação metafísica e política entre as culturas afro-americana e anglo-americana, que se manifesta em diferentes espaços, sendo a literatura um dos mais emblemáticos. Autores e críticos afrodescendentes inspirados em fontes da tradição ocidental - produzem obras que remetem a outras; a tradição literária afrodescendente, entretanto, tem um traço exclusivo, pois "sempre repete com uma diferença - uma diferença negra que se manifesta no seu uso próprio da língua". (GATES, 1988, p.xii; xiii, trad. livre). Lançando mão da prática cultural afro-americana de $\operatorname{Signifyin}(g)$ - jogo de palavras, estratégia verbal comum entre os afro-americanos de utilização de linguagem metafórica -, o crítico elabora uma teoria sobre práticas contradiscursivas de grupos afrodescendentes nos EUA.

14. MOORE (2000) e SANDIFORD (1991) apresentam leituras valiosas sobre algumas das simbologias em Linden Hills.

15. Iniciada em 1307, e concluída por volta de 1321, A Divina Comédia é um poema épico em italiano, que narra a odisseia do poeta ao Inferno, Purgatório (aos quais é conduzido pelo poeta Virgílio) e Paraíso, (aonde é levado por sua musa, Beatriz).

16. Street credibility, i.e., aceitação e respeito por parte de quem vive nos bairros menos privilegiados da cidade e conhece a lei de suas ruas.

17. "His favorite person in all history."

18. "[...] if he turned a just a shade darker, there was nothing he could do but start going the other way". 
19. "These niggers would be afraid to sweat".

20. "[...] he doubled the odds of finishing first if he didn't carry the weight of that milligram of pigment in his skin".

21. "Priceless information".

22. The Philadelphia Negro: A Social Study, de W.E.B. DuBois (1899), um dos primeiros trabalhos a combinar a etnografia urbana, história social e estatística descritiva, tornou-se um clássico na literatura das Ciências Sociais. Du Bois é considerado um dos precursores da Sociologia Americana.

23. "Yes, I've moved among them, eaten with them, laughed with them, but I've known my purpose here from the beginning and I've never let myself get too involved."

24. Sua postura remete, ainda que subliminarmente, à dos primeiros etnógrafos europeus, que, a princípio, recebiam informações sobre outros povos sem sair de sua terra. Quando passaram a acompanhar as expedições, observavam 'de longe', sem se envolver com a comunidade estudada (cf. URIARTE, 2012). O que causa estranhamento é o fato de que, ao contrário daqueles, o historiador de Linden Hills não é o Outro ali.

25. "[...] six lines of credit in his name, never questoning what she bought or why. And he asked so little of her in return. [...] respect him and the routines of his household".

26. "O Blessed Saviour, can it be that I have only exchanged one master for another? Can it be that in the innocent scribblings I sought only to hide from a husband's amused contempt are now the diary of a slave?"

27. "A História da Escravidão Negra no Brasil”. Revista Geledes online, 2012.

28. A alteridade das mulheres Nedeed (e das mulheres do romance de Naylor em geral) é, evidentemente, incontestável; entretanto, optamos por não desenvolver o tema, visto não ser este o foco deste trabalho.

29. Criadora do conceito de pós-memória, utilizado pela primeira vez em um artigo em Maus (Art Spiegelman, 1986), que se refere à memória das gerações que não viveram o trauma (do Holocausto), mas que o receberam como herança, por meio de histórias, imagens e comportamentos de seus antecessores Cf. <https://www. postmemory.net>. Em seu livro mais recente, The Generation of Postmemory: Writing and Visual Culture After the Holocaust (Columbia UP, 2012), que tem a participação de historiadores, artistas e escritores, a autora propõe a discussão de temas como memória, trauma e gênero lançando mão tanto de textos como de imagens.

30. Solis (2014, p. 383) defende que todo pesquisador/investigador sofre de mal de arquivo e, por isso, é compelido "a prosseguir por mais que os dados articulados no arquivo joguem ou concorram para fazê-lo abandonar o fio e desistir".

31. "Luther: 21 years. She was no longer recording the growth of a child; the only thing growing in these pictures was her absence".

32. Aqui nosso diálogo é, evidentemente, com O homem invisivel, de Ralph Ellison (Trad. Mauro Gama. 1. ed. Rio de Janeiro: José Olympio, 2013. Primeira publicação: Random House, 1952). Reputado como uma das maiores obras do século XX, o livro abre o arquivo da experiência do afrodescendente nos Estados Unidos, ao propor um enredo que faz uma varredura em temas filosóficos, psicológicos e sociais, que configuram as agruras enfrentadas pelos afroamericanos no começo do século XX. Seu narrador-protagonista parte do sul em busca de reconhecimento e sucesso em Nova York, mas, após sucessivos reveses, ele cai em um buraco urbano (fugindo da polícia) e passa a habitá-lo. Neste porão de isolamento, ele, assim como Willa, tem seu discernimento descortinado. Paradoxalmente, sua cor negra era o fator determinante de uma invisibilidade que ele demorou a enxergar. 


\section{Referências}

BALDWIN, James. The Evidence of Things not Seen. Henry Holt and Company, Inc. New York: 1985.

BENJAMIN, Walter. Rua de mão única - Obras escolhidas II. Tradução de Rubens Rodrigues Torres Filho; Jose Carlos Martins Barbosa. São Paulo: Brasiliense, 2000.

BENTHAM, Jeremy. The Panopticon Writings. 1787. Introd. e ed. Miran Božovič. London: Verso, 1995.

BRADLEY, Harriet. The Seductions of the Archive: Voices lost and found. History of the Human Sciences, v. 1, n. 2, p. 107-122. London; Thousand Oaks, CA; New Delhi: SAGE Publications, 1999.

BUONAIUTO, Claudia. Archival Sounds: Caryl Phillips's Atlantic Story. Anglística, v. 8, n. 1-2, p. 11-28. Annali Istituto l'Orientale Napoli, 2004.

DERRIDA, Jacques. Mal de arquivo. Trad. Claudia de Moraes Rego. Rio de Janeiro: Relume Dumará, 2001.

EATON, Kalenda. Diasporic Dialogues: The role of gender, language, and revision in the neo-slave narrative. Language Value, v. 4, n.2, p.1-22, 2012. Disp.: http:// www.raco.cat/index.php/LanguageValue/article/viewFile/302094/391705. Último acesso: 10/04/2017.

ENGLES, Tim. African American Whiteness in Gloria Naylor's Linden Hills. African American Review, v.43, n. 4 (Winter 2009), p. 661-679. St. Louis University, 2009. Disponível em http://www.jstor.org/stable/41328664. Último acesso: 18/04/2016.

FOUCAULT, Michel. The Archaeology of Knowledge and the Discourse on Language. Translated from the French by: A.M.Sheridan Smith. New York: Pantheon Books, 1972.

GATES, Jr. Henry Louis. The Signifyin(g) Monkey. Oxford UP, 1988.

JOHNSON, Erica. Building the Neo-Archive: Dionne Brand's A Map to the Door of No Return. Meridians: feminism, race, transnationalism, v. 12, n. 1, p. 149-171, 2014.

HAWKINS, Christiane. Historiographic Metafiction and the Neo-slave Narrative: Pastiche and Polyphony in Caryl Phillips, Toni Morrison and Sherley Anne Williams. FIU Electronic Theses and Dissertations. Paper 741. Florida International University, 2012.

HIRSCH, Marianne. Surviving Images. Holocaust Photographs and the Work of Postmemory. The Yale Journal of Criticism. v. 14. n. 1. p.5-37. Yale University and The Johns Hopkins University Press, 2001.

LYSIK, Marta. You Have Seen How a [Wo]man Was Made a Slave; You Shall See How a Slave Was Made a [Wo]man. Alice Walker's The Color Purple as a NeoSlave Narrative. American Studies. v. XX. p. 17-34, 2004. Disp: www.asc.uw.edu. pl/theamericanist/vol/21/21_17-34.pdf. Último acesso: 29/11/2016.

MANOFF, Marlene. Theories of the Archive from Across the Disciplines. Libraries and the Academy, v. 4, n. 1, p. 9-25. Baltimore: The Johns Hopkins UP, 2004.

McKEEVER, Sara. "Linden Hills: Where Happiness Comes to Die". Working paper acessado através do portal da DePaul University: http://students.depaul. edu/ smckeeve/hci201/ePortfolio/reflection_on_linden_hills $>$. Último acesso: 01/02/2018.

MOORE, John Noel. Myth, Fairy Tale, Epic and Romance: Narrative as Re-Vision in Linden Hills. Callaloo. v. 23, n. 4. p. 1410-1429. Baltimore: The Johns Hopkins UP, 2000. 
NORA, Pierre. 1993. Entre Memória e História. A problemática dos lugares. Trad. Yara Aun Khoury. Projeto História, p.1-22. São Paulo, 1993.

NAYLOR, Gloria. Linden Hills. New York: Penguin, 1985.

OSBORNE, Thomas. The Ordinariness of the Archive. History of the Human Sciences, v.12, n.2. p.51-64. London, Thousand Oaks and New Delhi: Sage Publications, 1999.

REVISTA GELEDÉS [online], INSTITUTO DA MULHER NEGRA. A história da escravidão negra no Brasil. Disponível: https://www.geledes.org.br/historia-daescravidao-negra-brasil/. Último acesso: 30/1/2018.

SANDIFORD, K.A. Gothic and Intertextual Constructions in Linden Hills. Arizona Quarterly: A Journal of American Literature, Culture, and Theory, v.47, n. 3, p. 117139. U of Arizona P, 1991.

SCHWARTZ, Joan M. "Having New Eyes": Spaces of Archives, Landscapes of Power. Archivaria - The Journal of the Association Canadian Archivists, n. 61. p. 1-25. Special Section on Archives: Space and Power, 2006.

SOLIS, Dirce Eleonora Nigro. Tela desconstrucionista: arquivo e mal de arquivo a partir de Jacques Derrida. Filos, v. 26, n.38, p.373-389, 2014.

URIARTE, Urpi Montoya. O que é fazer etnografia para os antropólogos. Ponto Urbe [online]. Revista do Núcleo de Antropologia Urbana da USP, n.11. São Paulo, 2012. p. Último acesso: 10/03/2017.

WRIGHT, Gwendolyn. Building the Dream: A Social History of Housing in America. Cambridge, MA: MIT Press, 1983. 